\title{
As políticas de inclusão como problemática de engajamento antropológico
}

\section{The politics of inclusion as a problem of anthropological engagement}

\section{Patrice Schuch ${ }^{*}$}

* Universidade Federal do Rio Grande do Sul - Porto Alegre, RS, Brasil patrice.schuch@gmail.com

Ceres Gomes Víctora**

** Universidade Federal do Rio Grande do Sul - Porto Alegre, RS, Brasil ceresvictora@gmail.com

Sergio Baptista da Silva ${ }^{\star * *}$

*** Universidade Federal do Rio Grande do Sul - Porto Alegre, RS, Brasil sergiobaptistadasilva@gmail.com 
A temática deste número de Horizontes Antropológicos - "Políticas de inclusão" - comemora a edição do número 50 da revista e reúne trabalhos que analisam, predominantemente a partir dos referenciais da antropologia social, um conjunto heterogêneo de programas, projetos e ações dirigidos a inscrever determinadas pessoas e populações como alvos de atenção e de políticas públicas. Trata-se de uma temática cuja relevância acadêmica e política no Brasil cresceu a partir do processo de redemocratização social e política, ocorrido ao longo dos anos 1980. No bojo desse processo, novas ênfases de engajamento e pesquisa etnográfica surgiram no país, como os campos dedicados à análise da política, do direito, da ciência, bem como outros mais clássicos foram revigorados a partir de um conjunto original de reflexões que abarcou a agência política de populações tradicionais brasileiras, como indígenas e quilombolas, na luta por seus direitos. Nesse caminho, renovaram-se as reflexões sobre o próprio fazer antropológico, seus desafios, práticas e políticas, bem como suas formas de engajamento no espaço público na abertura de espaços menos marcados por relações de poder.

Percebe-se a transversalidade da temática, que perpassa os "campos" mais sólidos de conhecimento antropológico e dialoga com outras disciplinas, como a ciência política, a sociologia, o direito e as políticas públicas. Embora uma perspectiva transversal seja imprescindível, este dossiê convida a um olhar mais específico sobre o tema e propõe uma reflexão sobre a pertinência dessa problemática na análise antropológica e a partir da relação com os debates promovidos por outras disciplinas. Acreditamos que é bem-vinda a agregação de trabalhos que têm por fim discutir, através de pesquisas empíricas, os pressupostos, os modos de funcionamento, os saberes, as rotinas, as experiências e os efeitos das políticas de inclusão constituídas no Brasil, em perspectiva etnográfica ou comparativa, realizadas principalmente (mas não exclusivamente) após recente período de restauração democrática. Ainda que não tenhamos a intenção de homogeneizar processos que são, por suas características, eminentemente heterogêneos - como bem mostrarão os artigos a seguir - é nossa aposta que vale a pena perguntar: afinal, após mais de 30 anos de políticas que se pretendem "inclusivas" no Brasil, quais seus sentidos, mecanismos e formas de ação, bem como seus efeitos na vida social e política? E também: quais as maneiras com que a antropologia, em colaboração com outras ciências sociais, engaja-se nesse debate e eventualmente dinamiza suas posições metodológicas, conceituais e políticas? 
Em termos gerais, é possível identificar alguns trabalhos já publicados no Brasil que dialogam com a ideia deste dossiê, os quais não se dirigem propriamente ao estudo das "políticas de inclusão", mas intersectam com a nossa proposta de maneira substantiva. Há um texto que avalia a área temática da antropologia da administração e da governança no Brasil, escrito por Teixeira e Souza Lima (2010), em coletânea editada pela Anpocs. Existe também o "Dossiê Fazendo Estado", publicado na Revista de Antropologia da USP, em 2012, organizado por Souza Lima (2012), que conclama ao estudo do Estado a partir das práticas e políticas de governo. Em 2015, foi publicado um artigo na Revista Anthropológicas, escrito por Souza Lima e Macedo e Castro (2015), que diagnostica que o tema das políticas públicas não tem gozado de grande prestígio na hierarquia dos objetos de pesquisa no Brasil. Os autores também propõem uma leitura das categorias analíticas das disciplinas mais próximas ao campo de estudo das políticas públicas, contrastando-as com as categorias metodológicas e analíticas da antropologia. Não por acaso, a seção Espaço Aberto deste número possui um artigo escrito por Antonio Carlos de Souza Lima, a convite dos editores, detalhando as abordagens analíticas por ele utilizadas e os desafios nessa área de estudos.

Intersectando com a temática desse dossiê, destacamos ainda a coletânea organizada por Fonseca e Machado (2015) acerca da relação entre ciência, identificação e tecnologias de governo. A coletânea reúne artigos com objetivo de problematizar a interseção entre subjetividades, configurações de cidadania, controle estatal das populações e práticas de governo. Nessa direção, existe também o número temático sobre "Tecnologias de governo: etnografia de práticas e políticas", publicado em Horizontes Antropológicos, em 2016, organizado por Fonseca, Jardim, Schuch e Machado (Fonseca et al., 2016), o qual convida à pesquisa acerca das práticas e engrenagens das formas de intervenção destinadas a guiar, dirigir, orientar, capacitar e regular os sujeitos, populações e problemáticas. É relevante referir, entretanto, que há um conjunto mais amplo e profícuo de outros artigos e capítulos de livros que, embora não reunidos a partir de coletâneas ou dossiês sobre temas determinados ou mesmo dirigidos ao debate em torno das "políticas de inclusão", são inspirações relevantes para a efetivação deste dossiê, na medida em que propõem análises etnográficas sobre programas e projetos de intervenção social cuja justificativa-mor é a "inclusão" de sujeitos e populações no âmbito do governo. 
Seguindo tais inspirações, mas apostando na riqueza de uma abordagem mais específica sobre "políticas de inclusão", apresentamos este dossiê dirigido à análise de programas e projetos destinados a "incluir" e inscrever determinados sujeitos e populações como alvos de atenção e de políticas públicas. Considerando as obras já existentes, bem como a proposta de debate aqui formulada, é possível identificar três frentes de engajamento possíveis e que, propomos, constituem oportunidades de adensamento de reflexões sobre o assunto: a primeira, que diz respeito às formas de "fazer" o Estado e as políticas públicas; a segunda, que se refere aos modos e sentidos da mobilização política de sujeitos e populações; e, por fim, a terceira, que se interessa em debater os efeitos das práticas e políticas de inclusão. A potência das etnografias das formas de mobilização política, das configurações das burocracias e economias morais envolvidas na promoção e implantação de projetos e programas de inclusão, bem como dos estudos sobre os efeitos das práticas e políticas de inclusão, faz perceber que não é possível dissociar completamente tais frentes de debate. Entretanto, para fins de circunscrição da temática é válida a diferenciação, pensada, portanto, apenas na relação com conjuntos de debates mais específicos sobre o assunto, os quais revelam a potência do estudo desse tema.

A ênfase analítica nas formas de "fazer" o Estado e as políticas públicas leva a interrogações etnográficas sobre como se dá a sua constituição contínua através de programas e projetos, da heterogeneidade do funcionamento de burocracias e das economias morais que lhes sustentam. Também se incluem as análises que focalizam as técnicas, saberes, categorias e agentes mediadores que possibilitam a existência cotidiana de práticas, infraestruturas, aparatos e rotinas governamentais e não governamentais. Essas, muitas vezes, extrapolam os domínios nacionais propriamente ditos através das ênfases no "desenvolvimento", governança e cooperação internacional, o que impõe novos desafios à prática de pesquisa (Ferguson, 1994; Gupta, 2012; Gupta; Ferguson, 1992; Sharma; Gupta, 2006; Trouillot, 2001).

Nesse âmbito, a literatura antropológica, ao adentrar o domínio dos estudos sobre o Estado - classicamente atribuído ao campo da ciência política e da sociologia - tem contribuído para mostrar o quanto é imprecisa a noção de um Estado transcendente e homogêneo (Das; Poole, 2004; Gupta, 2012; Herzfeld, 1992; Sharma; Gupta, 2006; Souza Lima, 2012) e como tecnologias, dispositivos, burocracias, tempos e espaços produzem o "efeito Estado" 
(Mitchell, 1999) na sua transcendência e completude. Entender a produção do Estado é, pois, compreender simultaneamente suas infraestruturas de governo e suas narrativas soberanas (Gupta, 2012), a produção de representações sobre Estado e produção de práticas de governo em interações cotidianas entre agentes, tecnologias, expertises (Fonseca et al., 2016; Sharma; Gupta, 2006; Souza Lima, 2012).

Por sua vez, a vertente que privilegia os modos e sentidos da mobilização política de sujeitos e populações traz para o centro do debate as experiências e usos das políticas de inclusão pelos sujeitos e populações atingidas e a transformação de ideários e programas através das práticas de sua existência. Além de evidenciar que as já denominadas "margens" do Estado o coproduzem ativamente (Das; Poole, 2004; Schuch, 2015), essa frente de debates coloca interrogações importantes acerca de perspectivas transcendentes e centralizadoras sobre $o$ funcionamento do poder. Lembramos aqui da clássica abordagem acerca do poder político, desenvolvida por Pierre Clastres e publicada em 1974 no livro A sociedade contra o Estado, a partir de seus estudos sobre sociedades indígenas na América do Sul. Ao compreender as práticas de evitação (e não falta) do Estado nas sociedades ameríndias como recusa à centralização e transcendência do poder, o autor abre caminhos originais na problematização das formas de constituição do poder político para além do Estado. A atualidade da obra de Clastres (1974) se revela neste dossiê, acreditamos, nas possibilidades de pensar dinâmicas de inclusão política de sujeitos e populações que podem trabalhar simultaneamente a partir, contra e para além do próprio Estado.

Essa segunda perspectiva analítica também dialoga com os trabalhos mais clássicos provenientes do campo de estudos sobre políticas públicas. Tal como bem colocado pelo antropólogo Cris Shore (2010), a produção e implementação de políticas públicas é uma atividade sociocultural por excelência, profundamente imersa em processos sociais cotidianos e nos mundos de sentido dos agentes envolvidos, os quais têm posições e disposições variadas. Para o autor, isso significa que a análise das políticas públicas implica dar sentido ao conhecimento tácito e às múltiplas interpretações e definições dos atores envolvidos, que algumas vezes podem estar em conflito (Shore, 2010). Segundo Shore (2010), esse entendimento de políticas inclui analiticamente a experiência das pessoas envolvidas - o que é um ponto relevante nos trabalhos que dialogam com agentes de intervenção e 
acadêmicos da área das políticas públicas e desenvolvimento, também referido por Biehl e Petryna (2013) em coletânea sobre o assunto. A percepção de que as políticas são perpassadas por valores, mediações e ambiguidades em seu processo de efetivação produz uma série de rupturas com os modos como usualmente a literatura da área tratou o assunto, que Shore (2010) sintetiza nas visões: positivista (que associa o trabalho de produção de políticas somente às elites governamentais e restringe a análise das políticas em torno das questões sobre como governam os governantes); clínica (que percebe as políticas a partir de uma aproximação clínica, isolando-as das práticas sociais); e linear (que analisa as políticas a partir de uma ênfase numa cadeia lógica de eventos que inicia na formulação e chega até a recepção dessas políticas pelos "usuários").

Por fim, a vertente analítica que enfatiza os efeitos das práticas e políticas de inclusão interessa-se em compreender os efeitos heterogêneos das políticas de inclusão na constituição de novas categorias, saberes, moralidades e tecnologias de gestão da vida de indivíduos e coletivos. Nesse âmbito, acreditamos que a discussão mais relevante e provocativa é, efetivamente, em torno dos sentidos atribuídos à "inclusão". Em sua obra clássica Homo sacer: o poder soberano e a vida nua I, Giorgio Agamben (2002) leva adiante as discussões formuladas por Michel Foucault sobre biopolítica e disserta sobre uma figura do direito romano arcaico - o "homo sacer"/vida nua - considerado uma vida matável, mas não sacrificável. Explica Agamben (2002) que o "homo sacer" era uma figura humana que estava incluída no ordenamento político unicamente a partir de sua exclusão.

A argumentação do autor é longa e complexa, ao afirmar a implicação da vida nua na esfera política, a qual constituiria o núcleo originário (embora oculto) do poder soberano. Para ele, a estrutura da exceção - uma forma externa de relação que inclui alguma coisa unicamente através de sua exclusão - seria consubstancial à política ocidental. Embora o argumento seja constituído a partir dos diálogos da filosofia política e alguns antropólogos já tenham destacado sua falta de precisão histórica e ampla generalidade argumentativa (Das; Poole, 2004; Ong; Collier, 2005), acreditamos que as suas interrogações acerca do dinamismo entre inclusão-exclusão podem ser pertinentes à análise antropológica das políticas de inclusão - e inclusive acerca dos seus próprios sentidos. 
Em texto sobre a problemática da inclusão-exclusão, a cientista política Celi Pinto salienta que essa problemática apresenta uma dupla natureza: trata-se tanto do que chama de pseudocategorias sociológicas convenientemente utilizadas a partir da década de 1990 por políticos e interventores, como se trata de duas noções explicativas das formas de constituição de relações de poder, na proposta analítica de Michel Foucault. Para a autora, a partir dos anos 1990 a noção de "exclusão" substituiu, com vantagens, uma série de outras denominações de agentes sociais que estavam marcados, ao longo da história, por lutas, por oposições, por relações de poder perversas. Para ela, há duas consequências desse processo:

[...] a primeira é que o excluído perde sua unidade corpórea. Todos podem ser excluídos de alguma situação e incluídos em outra, não existe alguém completamente incluído ou completamente excluído; a segunda consequência relaciona-se ao fato de o excluído não ter seu contraditório, sua oposição, seu antagônico: o proletariado não objetiva ser burguês, daí a possibilidade da relação antagônica; o excluído não se antagoniza com o incluído, ao contrário, luta para se tomar um deles. (Pinto, 1999, p. 34).

Para a autora, o binômio inclusão-exclusão teria o poder de obscurecer determinadas contradições e dificultar sua expressão e até mesmo impedir sua constituição. Não obstante, a partir das reflexões sobre o processo de inclusão-exclusão seria possível compreender as formas de exercício do poder político. Nessa direção, a autora chama a atenção para a potência da análise das questões específicas da exclusão e da inclusão como noções explicativas das formas de exercício de poder, ao que Pinto (1999) atribui genealogicamente as influências do filósofo Michel Foucault.

Para além das contribuições mais específicas sobre a constituição do Estado como resultado das práticas de governo e da superação de uma analítica do poder concentrada nas suas atribuições repressivas, Foucault (1999) analisa os processos de exclusão e inclusão dos indivíduos através de medidas tomadas na Idade Média em relação aos leprosos e aos doentes da peste. Contrasta o "modelo da exclusão" dos leprosos na Idade Média - que separava e desqualificava jurídica e politicamente os sujeitos com lepra dos demais sujeitos - com o "modelo da inclusão", dirigido aos portadores da peste, que trabalhava com o 
controle a partir do conhecimento e do exame. O autor analisa as dinâmicas da inclusão-exclusão como formas de acesso aos mecanismos, estratégias e tecnologias de poder. Salienta, também, que a partir do século XVIII cresce a importância das formas de exercício de poder baseadas no modelo da "inclusão", que passa a conviver com as formas do modelo da "exclusão", as quais não desaparecem. Demonstrando a riqueza da atenção para formas de exercício de poder que se realizam através de outros elementos que não as estratégias repressivas, o autor contribui para dinamizar as análises sobre os sentidos das "políticas da inclusão" e suas ambiguidades.

Nessa direção, estudos mais recentes sobre biopolítica desenvolvem os argumentos foucaultianos em outros rumos. Akhil Gupta (2012), por exemplo, escreveu sobre as políticas de desenvolvimento na Índia e interrogou-se: como é possível a grave permanência de pobreza, e seus efeitos de má nutrição e índices surpreendentes de mortalidade, mesmo que haja uma profusão de programas e projetos de "inclusão" e de "desenvolvimento" no país? Destacando a importância da análise das "infraestruturas" de governo e os efeitos não apenas de produção da indiferença (Herzfeld, 1992), mas de contingência e arbitrariedade nas ações burocráticas, Gupta (2012) persegue as análises de Kleinman, Das e Lock (1997) ao referir que muitas vezes as políticas podem não apenas não resolver determinados problemas considerados importantes, mas também agravar o próprio sofrimento dos atingidos. Também nesse trabalho o sentido de "inclusão" é, eminentemente, ambíguo e dinâmico, o que acresce sua importância como tema de debate e engajamento antropológico.

Analisadas em conjunto, é possível referir que em todas as três frentes de abordagens sobre o tema enfatizadas aqui os sentidos associados à "inclusão" não são unívocos ou mesmo fixos. Isso implica que o espaço da heterogeneidade de sentidos, de técnicas e tecnologias, rotinas e infraestruturas cotidianas de sua realização, bem como de agentes, formas de mobilização e de luta política, se torna aberto para análises que problematizam molduras mais fixas ou transcendentes sobre o estudo do Estado e das políticas. E aqui se revela a potência da velha e boa etnografia, na medida em que nos parece que é nas dinâmicas das práticas, mediações e contingências que podemos encontrar os sentidos efetivos da "inclusão" - e não em cartilhas políticas dos projetos de intervenção ou simplesmente nos conceitos abstratos e, muitas vezes, transcendentes às próprias práticas, dos livros acadêmicos. 


\section{Políticas de inclusão: olhares a partir das dinâmicas das práticas}

É nesse sentido que apresentamos os textos que compõem este dossiê, os quais não se propõem a qualquer olhar generalizante acerca das "políticas de inclusão", mas apostam na relevância de uma análise mais específica sobre práticas, formas de ação e valores associados à "inclusão".

Um primeiro conjunto de textos dedica-se à compreensão das formas de "fazer" o Estado e as políticas públicas. No texto "Estados imaginados' e novas virtudes: notas sobre a construção das políticas de transparência e combate à corrupção", Simone Magalhães Brito apresenta sua pesquisa de campo realizada em dois órgãos de controle, um estadual e outro federal, destacando a economia moral da auditoria pública e as práticas de produção de transparência por parte do Estado. Os (des)encontros com os diferentes agentes do órgão estadual descritos no primeiro caso etnográfico indicam que a produção da transparência, longe de se materializar em práticas e rotinas de revelação, aproxima-se mais de um jogo de sombras e de produção de opacidades. Já na Controladoria Geral da União, o segundo caso pesquisado, as portas abertas, as longas entrevistas e aparente apresentação desproblematizada das rotinas e os sistemas por parte dos funcionários desvelam outras nuances do devir de um Estado aberto e transparente. As análises de Brito sugerem, em consonância com literatura socioantropológica sobre o Estado e suas rotinas, a "construção da transparência como um projeto marcado por tensões e níveis distintos que se articulam no cotidiano das atividades burocráticas".

No artigo de Tiemi Kayamori Lobato, intitulado "Políticas em movimento: instituições, ações de estado e servidores públicos indígenas na Secretaria de Estado para os Povos Indígenas do Amazonas (Seind/AM)", tem-se a descrição e análise da formação, constituição, funcionamento e extinção de uma instituição da administração pública brasileira, desde sua fundação, em 2009, até seu término, em 2015. A autora explora e discute as práticas e experiências de agentes estatais, indígenas e não indígenas, nas formas de "fazer" estado e políticas públicas voltadas ao atendimento de suas reivindicações, refletindo, em última instância, sobre suas presenças em entidades estatais onde “'indígenas' e 'estado' são colocados a existir juntos".

Fagner Carniel, por sua vez, em "Agenciar palavras, fabricar sujeitos: sentidos da educação inclusiva no Paraná", analisa a construção da política 
educacional para pessoas surdas, levando em conta sua participação como técnico na Secretaria de Estado da Educação do Paraná, e a interlocução que manteve com profissional dessa secretaria, cujo envolvimento com a gestão pública de inclusão educacional foi intenso e ativo ao longo de quase uma década. Nesse sentido, o texto discute o projeto institucional que tinha como objetivo incluir no ensino básico pessoas surdas, em categorias estáveis e passíveis de inclusão através da nomeação e normatização desses sujeitos.

Como uma segunda frente de abordagem do tema, temos os artigos mais diretamente vinculados aos modos e sentidos da mobilização política de sujeitos e populações. $\mathrm{O}$ artigo de Juliana Blasi Cunha analisa o caso do projeto de reurbanização de favelas do Programa de Aceleração do Crescimento (PAC), tomando o caso etnográfico da criação do Complexo Pavão-Pavãozinho-Cantagalo, no Rio de Janeiro. Contextualizando as políticas habitacionais no Brasil, a autora recorda a orientação "de cima pra baixo" que marcava projetos de reurbanização no passado, contrastando com o PAC-Favelas no qual a gestão participativa é condição necessária e determinante para a realização de obras físicas. O título do artigo “'O projeto já chegou até nós pronto e não podemos mudar muita coisa!", parafraseando um líder local em uma das reuniões entre técnicos e moradores, entretanto, já denuncia o tipo de inclusão que ocorreu na prática quando da implementação do projeto, que acabou privilegiando as dimensões técnicas - alargamento de ruas, acessibilidade e adensamento do espaço urbano - desconsiderando saberes locais e formas de classificação do espaço por parte dos moradores. A pesquisa etnográfica desenvolvida revela as tensões entre a imagem de um território integrado, coeso e uniforme concebido pelo PAC e a percepção dos moradores que se mantêm fiéis aos ordenamentos originais das duas favelas, Pavão-Pavãozinho e Cantagalo. $\mathrm{O}$ artigo apresenta uma reflexão sobre a agência dos líderes e moradores da favela que, mesmo diante da participação protocolar que lhes é requerida nas reuniões com os técnicos do PAC, buscam na prática cotidiana alternativas para inclusão de demandas e objetivos próprios. Recusando a tentação de homogeneizar o "nós" (as lideranças) e o "eles" (o Estado), o artigo conclui chamando atenção para as múltiplas lógicas presentes no processo de negociação nesse projeto de intervenção urbana.

Maria Raquel Passos Lima, no artigo "Paradoxos da formalização: a inclusão social dos catadores de recicláveis a partir do caso do encerramento do aterro 
de Jardim Gramacho (RJ)", discute a interrupção definitiva das atividades do aterro de resíduos da localidade, chamando atenção para as contradições e paradoxos verificados no decorrer do processo. Apresenta inicialmente um histórico da emergência e inclusão da categoria "catador de materiais recicláveis" na Classificação Brasileira de Ocupações em 2002 e as decorrentes regulamentação profissional e inserção da categoria em políticas públicas de incentivo a cooperativas. Essa transmutação social "representaria a conversão da população de catadores de uma situação de marginalização e vulnerabilidade para a de inclusão social e cidadania através do trabalho em empreendimentos coletivos autogestionários". Um dos maiores da América Latina, o aterro de Jardim Gramacho estava funcionando há 34 anos à época da pesquisa, com impactos de ordem social, ambiental e urbanística muito significativos na região. Diante de um contexto tão complexo, Lima destaca a diversidade que caracteriza as economias da reciclagem, assim como os pertencimentos, posicionamentos e perspectivas dos catadores diante das disputas e negociações que se deram no processo de desativação do aterro. Com recursos municipais que tinham como objetivo garantir a "inclusão social" através da geração de alternativas de trabalho e renda aos catadores, o projeto previa o pagamento de indenização aos trabalhadores do local e a construção de um polo de reciclagem para as cooperativas da região. A autora destaca na conclusão alguns dos paradoxos desse tipo de empreendimento, que, no caso analisado, resultou em uma série de desvantagens para a população, entre eles o desemprego da maioria que não foi absorvida pelas cooperativas do novo polo, além da degradação do bairro onde nunca foram realizadas as obras previstas de construção de casas, serviços de água, saneamento e segurança.

A partir de pesquisa desenvolvida na fronteira entre o Brasil e o Paraguai, Valdir Aragão Nascimento e Sônia Maria Oliveira de Andrade discutem as táticas e as estratégias usadas por paraguaios para acessar os serviços do Sistema Único de Saúde brasileiro em Ponta Porã (MS). Em seu artigo "As armas dos fracos: estratégias, táticas e repercussões identitárias na dinâmica do acesso à saúde na fronteira Brasil/Paraguai", Nascimento e Andrade questionam a ideia simplista de que o uso por parte dos estrangeiros dos serviços de saúde no Brasil "onera irremediavelmente o sistema de saúde na fronteira". Sugerem, como contraponto, que existe, antes de tudo, um problema maior que diz respeito à ausência de políticas cooperativas e/ou de integração coerentes com as 
dinâmicas da fronteira. Para eles, é precisamente a falta de políticas de inclusão mais compreensivas que motiva o emprego de táticas por parte de estrangeiros para terem acesso aos recursos públicos de saúde no Brasil. Destaca-se, entre elas, o acionamento de redes de relações para obtenção por empréstimo de documentos de residência ou de declaração assinada por morador brasileiro atestando que o portador reside com o declarante para que possa ser usado $o$ serviço do SUS. As entrevistas realizadas dos dois lados da fronteira, longe de serem unânimes, revelam uma multiplicidade de opiniões por parte de brasileiros e paraguaios que indicam que, para além das nacionalidades, o que está em jogo para os fronteiriços são valores, moralidades e identidades sociais.

Em "Garantia de direitos e burocracias estatais: mediadores universitários, protagonistas quilombolas e a tradição em disputa", Luiza Aragon Ovalle e Yolanda Gaffrée Ribeiro, ao trazer à luz e ao debate questões decorrentes da redação conjunta de um projeto por antropólogas e moradores do Quilombo da Sacopã, discutem o papel de mediadores na captação, no direcionamento de recursos para essa comunidade e na articulação de diferentes campos de conhecimento, visando a construção de um espaço dialógico entre saberes distintos e a produção de tecnologias sociais, perseguindo a concretização de direitos de cidadania. Ao longo de seu artigo, as autoras etnografam a interlocução entre elas próprias e os quilombolas, no transcurso dos encontros para planejar, pensar e redigir os dois projetos em questão - um para a Delegação da União Europeia no Brasil, outro para a Secretaria Especial de Políticas de Promoção da Igualdade Racial -, refletem sobre os papéis dos vários atores envolvidos nesses processos, especialmente o desempenhado por antropólogos, e discutem o acesso à burocracia a partir de desigualdades sociais, o que pressupõe a hierarquização profunda entre saberes locais e campos de conhecimento disciplinares.

Por fim, o terceiro conjunto de textos reúne trabalhos que se interessam em discutir os efeitos das práticas e políticas de inclusão. Em seu artigo "Entre a ameaça e a proteção: categorias, práticas e efeitos de uma política de inclusão na Cracolândia de São Paulo" Marina Mattar Soukef Nasser analisa as práticas e categorias acionadas pelos agentes da intervenção ao selecionar pessoas com um perfil predefinido que as torna elegíveis a um programa de assistência social e de saúde destinado a habitantes e frequentadores daquele local. A partir do acompanhamento do caso de uma jovem não incluída no programa, a autora discute a produção de territorialidades, espaços e corpos verificados no 
processo de intervenção estatal. O plano de ação envolvia, ao mesmo tempo, a retirada dos barracos e limpeza (literal e figurativa) da Cracolândia e a mobilização de recursos para moradia, trabalho, assistência social e de saúde para um total de 150 usuários de crack que circulavam na região. Entretanto, várias pessoas, por diferentes razões, não se enquadravam no perfil, tendo sido atingidas somente pelo empreendimento de limpeza do local. Entre eles, Raísa, que apesar de viver na rua há 16 anos, não poderia ser incluída por não se enquadrar no perfil alvo da atuação do projeto, paradoxalmente chamada de "De Braços Abertos". Braços que para ela - por não ser mais usuária de crack, porque não estava grávida, nem tinha filhos pequenos - estavam fechados. Ofereceram-lhe outras alternativas assistenciais, no entanto, seu "conhecimento prático relacionado a vivências do passado" indicava serem elas pouco adequadas para suas dinâmicas de vida. A autora destaca que o caso em questão aponta para os efeitos do entrelaçamento das "políticas de inclusão [...] com formas de gestão dos espaços e populações urbanas".

O artigo de Claudia Fonseca, Lucia Mury Scalco e Helisa Canfield de Castro intitula-se "Etnografia de uma política pública: controle social pela mobilização popular" e tem como foco "os efeitos de um programa social voltado para a distribuição de alimentos entre pessoas consideradas em situação de insegurança alimentar no âmbito do Programa Fome Zero (PFZ) no Brasil", mais particularmente as dinâmicas do programa de "Compra com Doação Simultânea" (CDS). A partir de dois estudos de caso e de uma etnografia da infraestrutura com vistas a compreender a organização e funcionamento do próprio programa social, as autoras se perguntam sobre as estratégias acionadas pelos beneficiados para enfrentar a alteração na periodicidade da distribuição de alimentos que se verificou em 2014. O primeiro caso analisado trata de uma cozinha comunitária que funciona junto a uma Unidade de Triagem e Compostagem na zona leste da cidade de Porto Alegre. Quando as entregas escassearam, os trabalhadores, associados dessa cooperativa de recicladores de lixo, encontraram alternativas de doação e recursos extras para manter aberta a cozinha com produtos básicos, nesse caso o arroz e o feijão, e passaram a trazer de casa complementos tais como uma porção de carne, tomate, polenta. O segundo caso é o da Associação Comunitária do Morro da Cruz, que proporciona atividades culturais, de geração de renda e solidariedade comunitária, além de ser responsável pela distribuição dos alimentos do programa de CDS para as famílias mais pobres do 
bairro, precisamente aquelas que foram severamente atingidas pela redução do programa de compra e distribuição de alimentos. A fim de conhecer o universo dos gestores e compreender as alterações sofridas pelo programa, as pesquisadoras adentram o universo dos conselhos gestores, do Fórum Fome Zero e da Companhia Brasileira de Alimentos Conab/RS, deparando-se com um vasto emaranhado de problemas administrativos, burocráticos e logísticos que atuam sobre os gestores, o programa e os beneficiários, produzindo efeitos diversos.

No seu artigo, intitulado "Políticas de inclusão e relações com a diferença - considerações sobre potencialidades, transformações e limites nas práticas de acesso e permanência da UFG", Alexandre Ferraz Herbetta descreve e analisa algumas políticas de inclusão e de permanência ocorridas na Universidade Federal de Goiás e voltadas para coletivos culturalmente diferenciados. O autor compara o programa UFGInclui e a atuação do Núcleo Takinahakỹ de Formação Superior Indígena, refletindo sobre ambiguidades, potencialidades e transformações observadas na universidade e tecendo considerações sobre a necessidade de transformações estruturais, tanto políticas como epistemológicas, para a efetiva concretização dessas políticas afirmativas.

Por fim, o artigo de Moisés Kopper e Arlei Sander Damo, intitulado "A emergência e evanescência da nova classe média brasileira”, finaliza essa seção, debatendo a constituição e contestação da noção de "nova classe média" no Brasil por assemblages que envolveram saberes econômicos, sociológicos e antropológicos, esferas de planejamento de políticas públicas, institutos de pesquisa e novos mercados de consumo, em um cenário que ensejou possibilidades de mobilidade e de diminuição dos índices de desigualdade, ao longo da década de 2000. O âmago do artigo se localiza na evidência dos modos pelos quais ideias em torno dessa nova categoria classificatória circulavam em cadeias sociotécnicas e passavam de um registro ao outro: da ciência ao governo, do governo ao mercado e, novamente, de volta à ciência, para anunciar - e contestar - essa possível categoria de enunciação da mobilidade no país. Os autores apontam que, mesmo com o mais recente esgotamento das razões que levaram à mobilidade ascendente, a controvérsia analisada ensejou debates que extrapolaram a discussão sobre a conjuntura econômica, expondo sua produtividade para refletir sobre questões de economia moral em torno de como pensar o próprio país.

Tomados em conjunto, os artigos deste dossiê evidenciam que "inclusão" parece ser um termo polissêmico, muitas vezes utilizado em seu sentido 
positivado nas políticas de intervenção social e deveras impreciso na análise acadêmica. Assim como os autores dos textos aqui apresentados, não propomos nenhuma definição generalizante sobre o termo. O convite que fazemos -e os artigos deste dossiê levam adiante - é pela abertura de um espaço de interrogações sobre as implicações do estudo das "políticas de inclusão" e de diálogo sobre o tema. Acreditamos que a antropologia, a partir do potencial da etnografia, pode problematizar muitas certezas usualmente atribuídas a tais políticas. Por outro lado, permite dinamizar seu entendimento a partir da perspectiva dos agentes envolvidos e das evidências de como qualquer política é mediada e vivenciada diferentemente de acordo com condições e posições sociais dos agentes envolvidos. Também possibilita realizar um enquadramento histórico de programas e projetos, que eventualmente subsidie a avaliação dos processos e uma eventual recondução de rumos.

\section{O número 50 de Horizontes Antropológicos e suas celebrações}

Celebramos, portanto, a relevância da temática e o fato de Horizontes Antropológicos comemorar seu número 50 com um assunto que entrelaça de formas muito evidentes o trabalho acadêmico e político. Impossível não destacar, no encerramento desta apresentação, o avanço de políticas conservadoras no país que dizem respeito às políticas de gênero e de educação, às ameaças às conquistas constitucionais dos povos indígenas e quilombolas e às tentativas de criminalização de movimentos sociais no Brasil. Como pesquisadores e estudiosos, precisamos estar atentos a tais processos e renovar nossas formas de engajamento reflexivo sobre o tema.

Nessa direção, este número comemorativo também celebra o potencial crítico da antropologia na análise dos processos sociais e políticos do Brasil. Destacamos a seção Espaço Aberto, que conta com artigo de Antonio Carlos de Souza Lima, convidado pelos editores de Horizontes Antropológicos a escrever acerca de sua trajetória profissional. O texto aborda as suas linhas de trabalho como pesquisador dedicado à análise das políticas indigenistas, do Estado e da história da antropologia, bem como os desafios da antropologia no espaço público, considerando sua experiência como presidente da Associação Brasileira de Antropologia (gestão 2015-2016). 
Igualmente no Espaço Aberto, o artigo de Paula Ramos aborda, e também celebra, o longo e tradicional encontro e diálogo entre antropologia e arte, que vem ocorrendo no decurso destes 50 números de Horizontes Antropológicos e que já se constitui como uma das características mais marcantes da política editorial da revista.

Como mais uma celebração neste número tão especial, e reforçando o vínculo sempre perseguido entre imagem e temática do número, a presente edição traz, pela primeira vez na história de Horizontes Antropológicos, a obra de um artista ameríndio em sua capa. Trata-se de Jaider Esbell, jovem e talentoso escritor, produtor cultural e artista plástico macuxi, nascido em 1979 onde hoje é a Terra Indígena Raposa Serra do Sol, em Roraima, que tem participado de inúmeras exposições no Brasil e no exterior, e que vem se destacando pelo seu trabalho de arteativismo, tanto em coletivos indígenas como fora deles. Segundo ele próprio, seu propósito não é apenas pintar, mas seu trabalho tem como função principal "ser uma ponte entre o conhecimento da floresta, a grande comunidade indígena e o restante do mundo".

A obra presente em nossa capa intitula-se As máscaras xamânicas estão voltando, de 2017, e quer, conforme depoimento do artista, "instigar entre os povos originários as suas relações contemporâneas com a espiritualidade".

O número 50 de Horizontes Antropológicos também marca a renovação do Conselho Editorial, formado por alguns dos mais importantes nomes da antropologia mundial, cuja participação certamente ajudará a nortear nossa política editorial. Outrossim, estamos inaugurando um novo projeto gráfico. Além da criação de um logotipo, a atualização da identidade visual da revista inclui mudanças na tipologia e diagramação, procurando facilitar o acesso aos conteúdos e tornar sua leitura mais agradável.

\section{Referências}

AGAMBEN, G. Homo sacer: o poder soberano e a vida nua I. Belo Horizonte: Editora da UFMG, 2002.

BIEHL, J.; PETRYNA, A. (Ed.). When people come first: critical studies in global health. Princeton: Princeton University Press, 2013. 
CLASTRES, P. A sociedade contra o Estado. São Paulo: Cosac Naify, 1974.

DAS, V.; POOLE, D. (Ed). Anthropology in the margins of the State. Santa Fe: School of American Research Press, 2004.

FERGUSON, J. The anti-politics machine. Development and bureaucratic power in Lesotho. The Ecologist, London, v. 24, n. 5, Sept./Oct. 1994.

FONSECA, C.; MACHADO, H. (Org.). Ciência, identificação e tecnologias de governo. Porto Alegre: Editora da UFRGS: Cegov, 2015.

FONSECA, C. et al. Apresentação. Horizontes Antropológicos, Porto Alegre, ano 22, n. 46, p. 9-34, jul./dez. 2016.

FOUCAULT, M. Les anormaux. Paris: Gallimard, 1999.

GUPTA, A. Red tape: bureaucracy, structural violence, and poverty in India. Durham: Duke University Press, 2012.

GUPTA, A.; FERGUSON, J. Beyond "culture": space, identity and the politics of difference. Cultural Anthropology, Washington, v. 7, n. 1 p. 6-23, Feb. 1992.

HERZFELD, M. The social production of indiference: exploring the symbolic roots of Western bureaucracy. Chicago: The University of Chicago Press, 1992.

KLEINMAN, A.; DAS, V.; LOCK, M. (Ed.). Social suffering. Berkeley: University of California Press, 1997.

MITCHELL, T. Society, economy and the state effect. In: STEINMETZ, G. (Ed.). State/ culture: state-formation after the Cultural Turn. New York: Cornell University Press, 1999. p. 76-97.

ONG, A.; COLLIER, S. (Ed.). Global assemblages: technology, politics and ethics as anthropological problems. Oxford: Blackwell Publishing, 2005.

PINTO, C. R. J. Foucault e as Constituições brasileiras. Quando a lepra e a peste se encontram com nossos excluídos. Educação e Realidade, Porto Alegre, v. 24, n. 2, p. 33-57, jul./dez. 1999.

SCHUCH, P. A legibilidade como gestão e inscrição política de populações: notas etnográficas sobre a política para pessoas em situação de rua no Brasil. In: FONSECA, C.; MACHADO, H. (Org.). Ciência, identificação e tecnologias de governo. Porto Alegre: Editora da UFRGS: Cegov, 2015. p. 121-145.

SHARMA, A.; GUPTA, A. Rethinking theories of the state in the age of globalization. In: SHARMA, A.; GUPTA, A. (Ed.). The anthropology of the state: a reader. Oxford: Blackwell Publishing, 2006. p. 1-41. 
SHORE, C. La antropología y el estudio de la política pública: reflexiones sobre la "formulación" de las políticas. Antípoda: Revista de Antropología y Arqueología, Bogotá, n. 10, p. 21-49, enero 2010.

SOUZA LIMA, A. C. de. Introdução ao Dossiê Fazendo Estado. Revista de Antropologia, São Paulo, v. 55, n. 2, p. 559-564, jul./dez. 2012.

SOUZA LIMA, A. C. de; MACEDO E CASTRO, J. P. Notas para uma abordagem antropológica da(s) política(s) pública(s). Revista Anthropológicas, Recife, v. 26, n. 2, p. 17-54, 2015.

TEIXEIRA, C. C.; SOUZA LIMA, A. C. de. A antropologia da administração e da governança no Brasil: área temática ou ponto de dispersão?. In: DUARTE, L. F. D.; MARTINS, C. B. Horizontes das ciências sociais no Brasil: antropologia. São Paulo: Anpocs, 2010. p. 51-95.

TROUILLOT, M.-R. The anthropology of the state in the age of globalization. Close encounters of the deceptive kind. Current Anthropology, Chicago, v. 42, n. 1, p. 125-138, 2001. 